\title{
Safety and Efficacy from an 8 Week Double-Blind Trial and a 26 Week Open-Label Extension of Asenapine in Adolescents with Schizophrenia
}

\author{
Robert L. Findling, MD, MBA, Ronald P. Landbloom, MD, ${ }^{2}$ Mary Mackle, PhD, ${ }^{2}$ Wendi Pallozzi, MS, ${ }^{3}$ \\ Sabine Braat, MS, ${ }^{4}$ Carla Hundt, MD, ${ }^{5}$ Marianne Z. Wamboldt, MD, ${ }^{6}$ and Maju Mathews, MD ${ }^{5}$
}

\begin{abstract}
Objective: The purpose of this study was to evaluate the safety and efficacy of asenapine in adolescents with schizophrenia. Methods: In an 8 week, randomized, double-blind placebo-controlled trial, subjects (12-17 years of age) meeting Diagnostic and Statistical Manual of Mental Disorders, 4th ed., Text Revision (DSM-IV-TR) criteria for schizophrenia were randomized 1:1:1 to placebo, asenapine $2.5 \mathrm{mg}$ b.i.d., or asenapine $5 \mathrm{mg}$ b.i.d. Subjects who completed the 8 week acute study could participate in a 26 week flexible-dose asenapine-only open-label extension (OLE).

Results: A similar percentage of subjects completed treatment on day 56 ( $2.5 \mathrm{mg}$ b.i.d. $(n=98): 83 \% ; 5 \mathrm{mg}$ b.i.d. [ $n=106$ ]: $79 \%$; placebo [ $n=102]$ : 79\%). In the mixed model for repeated measures analysis of the primary end-point (with Hochberg correction for multiplicity), least squares (LS) mean differences between asenapine and placebo on the Positive and Negative Syndrome Scale (PANSS) total score at day 56 were not significant ( -4.8 for $2.5 \mathrm{mg}$ b.i.d., $p=0.070 ;-5.6$ for $5 \mathrm{mg}$ b.i.d., $p=0.064$ ). Significant improvement in the Clinical Global Impressions-Severity score was observed in the $5 \mathrm{mg}$ b.i.d. group versus placebo on day 56 ( $\mathrm{LS}$ mean $-0.3, p=0.024$ ). In the acute phase, $\geq 7 \%$ weight gain and the composite event of somnolence, sedation, and hypersomnia were more common in both asenapine groups than in the placebo group. Akathisia, fasting glucose elevation, and extrapyramidal syndrome were more common in the $5 \mathrm{mg}$ b.i.d. group than in the placebo group. There were no unexpected adverse events in the OLE, and PANSS total scores decreased by -16.1 points in the group previously treated with placebo $(n=62)$ and by -11.2 points in the continuous asenapine group $(n=131)$ from OLE baseline to week 26.

Conclusions: Although improvements in PANSS total score at day 56 of the acute phase were numerically greater for both asenapine 2.5 and $5 \mathrm{mg}$ b.i.d. than for placebo and were maintained in the OLE, the primary end-point did not achieve statistical significance in the acute phase. No new or unexpected safety concerns were detected during the acute phase or after an additional 26 weeks of asenapine treatment in the adolescent population with schizophrenia.
\end{abstract}

Clinical Trials Registry: NCT01190254 and NCT1190267 at ClinicalTrials.gov

\section{Introduction}

A LTHOUGH SCHIZOPHRENIA RARELY develops in children $<12$ years old, onset of schizophrenia occurs in adolescence for 20-30\% of patients (Hafner et al. 1993; Beratis et al. 1994; American Psychiatric Association 2004; Kumar et al. 2013). The diagnosis of schizophrenia in children and adolescents uses the same criteria as diagnosis in adults (McClellan et al. 2013). In addition to psychosis, a significant decline in social or occupational functioning is a component of the diagnosis of schizophrenia. In early-onset schizophrenia (EOS), functional deficits may include failure to achieve expected levels of interpersonal or cognitive development (McClellan et al. 2013). EOS tends to be characterized by more severe negative symptoms, greater neurocognitive impairments, and higher rates of chronic functional and social impairment compared with adult-onset schizophrenia (Frazier et al. 2007, 2012).

Several of the second-generation atypical antipsychotics used to treat schizophrenia in adults have demonstrated efficacy in adolescents with schizophrenia (Findling et al. 2008; Sikich et al. 2008;

\footnotetext{
${ }^{1}$ The Johns Hopkins University/Kennedy Krieger Institute, Baltimore, Maryland.

${ }^{2}$ Merck, Whitehouse Station, New Jersey.

${ }^{3}$ Merck, Whitehouse Station, New Jersey.

${ }^{4}$ Merck, Oss, The Netherlands.

${ }^{5}$ Forest Research Institute, an affiliate of Actavis Inc, Jersey City, New Jersey.

${ }^{6}$ University of Colorado/Children's Hospital Colorado, Aurora, Colorado.

Funding: These studies and data analysis were supported by funding from Organon USA Inc., a subsidiary of Merck \& Co., Inc.
}

(C) The Author(s) 2015; Published by Mary Ann Liebert, Inc. This Open Access article is distributed under the terms of the Creative Commons Attribution Noncommercial License (http://creativecommons.org/licenses/by-nc/4.0/) which permits any noncommercial use, distribution, and reproduction in any medium, provided the original author(s) and the source are credited. 
Haas et al. 2009a,b Kryzhanovskaya et al. 2009; Singh et al. 2011; Findling et al. 2012; Kumar et al. 2013). The 2013 American Academy of Child and Adolescent Psychiatry (AACAP) Practice Parameter for the Assessment and Treatment of Children and Adolescents With Schizophrenia recommends ongoing use of antipsychotic medications, in combination with psychotherapeutic interventions, for treatment of EOS; however, this guideline does not specifically recommend any particular agent or secondgeneration atypical agents over first-generation agents, and endorses further study (McClellan et al. 2013). Endocrine and metabolic adverse effects, such as weight gain, are potential side effects of atypical antipsychotics (De Hert et al. 2011), and long-term studies of the safety of second-generation antipsychotics in pediatric populations are needed.

Although schizophrenia is a chronic illness requiring long-term therapy, data from the Treatment of Early Onset Schizophrenia Spectrum disorders (TEOSS) study indicate that many adolescents with schizophrenia discontinue treatment with the currently available therapies because of intolerability or lack of effectiveness (Sikich et al. 2008; Findling et al. 2010); therefore, additional treatment options for the EOS population are needed. Asenapine is a sublingually administered second-generation atypical antipsychotic that is approved for acute and maintenance therapy in adults with schizophrenia (Potkin et al. 2007; Kane et al. 2010, 2011; SAPHRIS ${ }^{\text {TM }}$ prescribing information 2014). Safety and efficacy in adults with schizophrenia have been demonstrated in controlled studies using doses of 5 or $10 \mathrm{mg}$ b.i.d. The pharmacologic profile of asenapine, a dibenzo-oxepino pyrrole derivative of the tetracyclic antidepressant mianserin, is characterized by high affinity for and antagonism of serotonergic receptors and potent dopamine, $\alpha$ adrenergic, and histamine antagonism with low cholinergic activity (McIntyre and Wong 2012). Here, we report results from the first double-blind, randomized, placebo-controlled trial that evaluated the 8 week efficacy and safety of asenapine in adolescents (12-17 years of age) with schizophrenia. The safety profile of asenapine in these adolescents was further evaluated in a 26 week, flexible-dose, asenapine-only open-label extension (OLE) trial.

\section{Methods}

The 8 week randomized, placebo-controlled, double-blind, fixed-dose acute trial (ClinicalTrials.gov: NCT01190254) was conducted at 19 centers in the United States and 60 international centers (22 in India, 14 in Russia, 7 in Ukraine, 4 in Serbia, 3 in Colombia, 3 in Romania, 2 in South Africa, 1 in South Korea, 1 in Croatia, 1 in Mexico, 1 in Philippines, and 1 in Bosnia-Herzegovina) from April 2011 to April 2013. The 26 week single-arm, flexible-dose OLE (ClinicalTrials.gov: NCT1190267) was completed in October 2013. Ethics review boards from each participating center approved the study protocols prior to study initiation. Informed consent (subject's parent, legal guardian, and/or caretaker) and subject assent were documented by means of a written, signed, and dated informed consent form obtained before any trial procedures or assessments were performed. Subjects who turned 18 years old during the acute trial were asked to sign an additional informed consent after they turned 18, and these subjects were allowed to enter the OLE. The studies were conducted in accordance with the Declaration of Helsinki; good clinical practice guidelines; and applicable country and/or local statutes and regulations regarding ethical committee review, informed consent, and the protection of human subjects participating in biomedical research. An external Data Monitoring Committee (DMC) met quarterly to evaluate safety data in an unblinded fashion during the course of these trials; no stopping rules for efficacy were present. During the course of these two trials, the DMC did not identify any safety concerns that led to protocol amendments or changes in the conduct of the trials.

\section{Eight week randomized, double-blind, placebo-controlled, fixed-dose acute phase}

Adolescents with a confirmed diagnosis of schizophrenia were randomly assigned in a 1:1:1 distribution to placebo, asenapine $2.5 \mathrm{mg}$ b.i.d., or asenapine $5 \mathrm{mg}$ b.i.d. (Fig. S1) (see online supplementary material at http://www.liebertonline.com/jcap). The trial consisted of a 3-10-day screening/tapering period, an 8 week double-blind treatment period, and a 26 week follow-up period with contact (via telephone or a visit) 7 and 30 days after a subject discontinued prematurely or completed the acute phase without participating in the OLE. During the screening/tapering period, previously administered disallowed medications including antipsychotics; depot neuroleptics; antidepressants; benzodiazepines; mood stabilizers; stimulants and other attention deficit hyperactivity disorder medications; miscellaneous psychotropics; and herbal drugs/dietary supplements for depression, anxiety, and insomnia were tapered per protocol and discontinued. Use of concomitant short-acting benzodiazepines (lorazepam $4 \mathrm{mg}$ or equivalent; or diazepam $\leq 40 \mathrm{mg}$ /day in countries with no approved short-acting benzodiazepines) for relief of transient symptoms of agitation, anxiety, insomnia, restlessness, or akathisia, and anticholinergics or short-acting benzodiazepines to treat extrapyramidal symptoms was allowed during the trial.

Inclusion criteria. Subjects ages 12-17 years with a current Diagnostic and Statistical Manual of Mental Disorders, $4^{\text {th }}$ ed., Text Revision (DSM-IV-TR) diagnosis of schizophrenia (paranoid, disorganized, or undifferentiated subtype) were eligible to participate in the 8 week acute phase of the trial (American Psychiatric Association 2000). All psychiatric diagnoses specified in the inclusion/exclusion criteria were made according to DSM-IV-TR criteria by a psychiatrist experienced in child and adolescent psychiatric disorders or by a sponsor-approved qualified clinician. The diagnosis of schizophrenia was confirmed using the Schedule for Affective Disorders and Schizophrenia for School-Age ChildrenPresent and Lifetime Version (K-SADS-PL) by a second psychiatrist or qualified sponsor-approved professional. In addition, each subject was required to have the following scores at screening and baseline: A Positive and Negative Syndrome Scale (PANSS) total score $\geq 80$; a Clinical Global Impressions-Severity (CGI-S) scale score of $\geq 4$ (moderately ill); and a score of $\geq 4$ (moderate) on two or more of the five items on the positive subscale of the PANSS (delusions, conceptual disorganization, hallucinatory behavior, grandiosity, suspiciousness/persecution).

Exclusion criteria. Subjects who had been treated with clozapine for treatment-resistant schizophrenia were to be excluded. Subjects with a primary Axis I diagnosis other than schizophrenia or a comorbid Axis I diagnosis that was primarily responsible for current symptoms and functional impairment were excluded, as were subjects with an uncontrolled or unstable clinically significant general medical condition (eg, renal, endocrine, hepatic, respiratory, cardiovascular, hematologic, immunologic, or cerebrovascular disease, or malignancy) or an abnormal laboratory, vital sign, physical examination, or electrocardiogram (ECG) finding at 
screening that, in the investigator's opinion, precluded the subject's participation in the trial or could interfere with the interpretation of safety and efficacy evaluations. Subjects with uncontrolled or unstable diabetes or a clinically significant abnormal blood glucose concentration at screening or baseline also were excluded. Any subjects reporting suicidal ideation with intent, with or without a plan, in the past 2 months, or suicidal behavior in the past 6 months, as measured by the Columbia Suicide Severity Rating Scale (CSSRS), were excluded.

Dosing. During the 8 week double-blind treatment period, subjects randomized to asenapine received fast-dissolving blackcherry-flavored sublingual asenapine tablets; and subjects randomized to placebo received matching black-cherry-flavored sublingual tablets without asenapine. Subjects randomized to asenapine $2.5 \mathrm{mg}$ b.i.d. started that regimen on day 1 and continued it for the duration of the treatment period. Subjects randomized to asenapine $5 \mathrm{mg}$ b.i.d. received $2.5 \mathrm{mg}$ b.i.d. until the visit on day 4 , at which time the dose of asenapine was increased to $5 \mathrm{mg}$ b.i.d. for the evening dose; and the $5 \mathrm{mg}$ b.i.d. regimen was continued for the duration of the treatment period. Participants who could not tolerate the dose to which they were randomized were discontinued from study participation. Visits were scheduled on days $1,4,7,14,21$, 28,42 , and 56 during treatment.

Efficacy outcomes. The primary efficacy end-point was the change from baseline to day 56 in the PANSS total score. The PANSS is a 30 item instrument in which total scores range from 30 (all symptoms absent) to 210 (all symptoms extreme) (Kay et al. 1987). The key secondary end-point was the change from baseline to day 56 in the CGI-S of subjects' illness score. Possible CGI-S scores range from 1 (normal, not at all ill) to 7 (among the most extremely ill subjects) (Guy 1976). Decreases from baseline within a group are indicative of improvement for both the PANSS total score and the CGI-S score. Other planned secondary end-points included $30 \%$ PANSS responders, defined as a subject with a reduction from baseline of $\geq 30 \%$ in the PANSS total score, and the PANSS positive and negative (items P1-P7, and N1-N7, respectively, both with possible range of 7-49) subscale scores.

Safety outcomes. Selected adverse events (AEs) of interest included akathisia; dizziness; insomnia; somnolence, sedation, and hypersomnia combined; oral hypoesthesia and dysgeusia combined; extrapyramidal syndrome (EPS); and the occurrence of a clinically significant weight gain, defined as in increase of $\geq 7 \%$ from baseline to end-point. EPS was defined using a Standardized Medical Dictionary for Regulatory Activities (MedDRA) Query (SMQ [narrow]) that included akathisia, dyskinesia, dystonia, and Parkinson-like events. Narrow SMQs are intended to enhance specificity by being highly likely to represent the condition of interest (Introductory Guide for Standardized MedDRA Queries [SMQs] Version 15.1, 2012; Introductory Guide for Standardized MedDRA Queries [SMQs] Version 16.0, 2013). Subjects' suicidal symptoms and actions were evaluated with the C-SSRS at each visit.

Changes in body weight and body mass index (BMI) were also adjusted for growth (age and sex) and presented as mean and median $Z$ scores (Centers for Disease Control and Prevention 2000). Analysis of safety data also focused on mean changes from baseline and predefined levels for the following lipid and endocrine parameters: Fasting glucose, fasting triglycerides, fasting total cholesterol, prolactin, fasting insulin, and hemoglobin A1c (HbA1c). New-onset diabetes was assessed using the MedDRA hyperglycemia/new onset diabetes mellitus SMQ (broad), which also included the preferred terms increased appetite, weight increased, hypertriglyceridemia, and weight decreased. In addition, new-onset metabolic syndrome was assessed using International Diabetes Federation (IDF) criteria; subjects considered obese per the European waist circumference (girth) criterion ( $\geq 90$ th percentile in children $<16$ years of age or $\geq 94 \mathrm{~cm}$ for males and $\geq 84 \mathrm{~cm}$ for females $\geq 16$ years of age) plus exceeding the threshold for two or more specific laboratory values and/or blood pressure measures (ie, elevated triglycerides, low highdensity lipoprotein cholesterol, high blood pressure, and increased plasma glucose) were considered to have new-onset metabolic syndrome (International Diabetes Federation 2014).

Sample size and statistical analysis. The total target sample size was 300 subjects or 100 subjects per treatment group. With this sample size, the study would have $\geq 85 \%$ power to detect a difference between one or more asenapine doses and placebo of 8 points at day 56 on the change from baseline PANSS total score (ie, primary objective), assuming a standard deviation (SD) of $\sim 16$ at day 56 and a $40 \%$ dropout rate after 8 weeks in each group. A two sided significance level of 0.05 with multiplicity correction according to Hochberg procedure was applied as the decision rule. For allocation of subjects, a computer-generated randomization list was used. The randomization list was created by the sponsor using SAS statistical software, and was stratified by site with a $1: 1: 1$ allocation using a block size of 3 . Allocation of subjects and medication was done using an Interactive Voice Response System by an independent third-party vendor.

Efficacy end-points were analyzed for all randomized adolescents who received one or more doses of asenapine or placebo, and had both baseline and at least one postbaseline PANSS total score (full analysis set [FAS]). The primary and key secondary efficacy endpoints were analyzed with a mixed model for repeated measures (MMRM); the MMRM included terms for (pooled) site, treatment group, visit, treatment by visit interaction with baseline score, and visit by baseline score interaction as covariates; and an unstructured variance-covariance structure. PANSS 30\% responders were analyzed using logistic regression with treatment, baseline, and (pooled) site in the model (last observation carried forward). PANSS subscale scores were analyzed using an MMRM model similar to that of the primary and key secondary end-point. A subgroup analysis of PANSS total score at day 56 by region (United States vs. non-United States) also was conducted by including the interaction of treatment by region in the MMRM model. $P$ values for all end-points other than the primary, which was Hochberg corrected, were unadjusted.

Safety data were analyzed for all randomized adolescents who received one or more doses of the study drug (all-subjectsas-treated). Treatment-emergent adverse events (TEAEs) were reported, defined as AEs that occurred for the first time during the 8 week treatment period or were present during the screening period but worsened in severity during the treatment. All TEAEs, including those leading to discontinuation, and serious adverse events (SAEs) were summarized descriptively by MedDRA system organ class and preferred term. For TEAEs of interest, statistical comparisons were made between placebo and asenapine at the two sided significance level of $p<0.05$ using Miettinen and Nurminen (1985) for proportions with no correction for multiplicity.

\section{Twenty-six week, flexible-dose OLE}

Study design. Adolescents who completed the 8 week acute phase with an acceptable degree of adherence to trial medication 
and compliance with the protocol and who, in the investigator's judgement, could benefit from long-term treatment, were eligible to participate in the 26 week OLE (see Fig. S1). Subjects at imminent risk of self-harm or harm to others, in the investigator's opinion and based on C-SSRS responses, were excluded from the OLE. On day 1 of the OLE, all adolescents started with open-label asenapine at a dose of $2.5 \mathrm{mg}$ b.i.d. At the day 4 visit, the dose of asenapine was increased to $5 \mathrm{mg}$ b.i.d. From day 5, dosing was adjusted to either $2.5 \mathrm{mg}$ b.i.d. or $5 \mathrm{mg}$ b.i.d. based on tolerability and/or symptomatology as determined by the investigator. Visits during the OLE were on days 1, 4, 14, 28 (OLE week 4), 42 (OLE week 6), 70 (OLE week 10), 98 (OLE week 14), 126 (OLE week 18), 154 (OLE week 22), and 182 (OLE week 26) during treatment.

OLE efficacy and safety outcomes. Long-term safety and tolerability of asenapine therapy in adolescents were assessed for up to an additional 26 weeks, and summarized descriptively. The TEAEs and laboratory values of interest in the acute trial were also of special interest in the OLE. Exploratory descriptive analyses of efficacy parameters, including change in PANSS total score change and CGI-S and PANSS 30\% responders during the OLE, were conducted. Maintenance of PANSS 30\% response in the OLE also was analyzed for those subjects who were $30 \%$ responders during the acute phase. PANSS was assessed at OLE baseline and weeks 4, 10, 18, and 26; CGI-S and C-SSRS were assessed at each visit; weight and BMI were assessed at OLE baseline and weeks 2, 4, 10, 18 , and 26.

OLE statistical analysis. Safety data were reported for all enrolled adolescents who received one or more doses of the study drug and were $<18$ years of age at enrolment (all-subjectsas-treated). Efficacy data were reported for the FAS, defined as all enrolled adolescents who received one or more doses of asenapine, had both a baseline and at least one postbaseline PANSS total score, and were $<18$ years of age at enrollment. During the OLE, the average daily dose for each subject was calculated, and then the population mean, median, and mode of the average daily dose were derived. Efficacy and safety measures for the OLE were summarized separately for subjects previously treated with placebo in the double-blind acute phase (hereafter referred to as the placebo/ asenapine group) and those who were previously treated with double-blind asenapine (hereafter referred to as the continuous asenapine group). OLE baseline was used for calculating changes from baseline in efficacy parameters, and data were analyzed using an observed cases (OC) approach. TEAEs during the OLE were those that were newly reported during the OLE or were reported in the blinded phase but worsened in severity during the OLE; hence, this definition implies that an $\mathrm{AE}$ preferred term reported as starting and stopping during the acute phase and subsequently reemerging during the OLE with the same severity was not counted in the TEAE summaries for the OLE. Data from eight subjects (two in the placebo/asenapine group and six in the continuous asenapine group) who were 18 years old at the time of enrollment in the OLE were excluded from the main OLE efficacy and safety analyses, but were included in some analyses of change to OLE end-point when the acute phase baseline was the point of reference.

\section{Results}

\section{Subjects}

Eight week acute phase. A total of 306 subjects were randomized to treatment with placebo $(n=102), 2.5 \mathrm{mg}$ b.i.d. asenapine $(n=98)$, or $5 \mathrm{mg}$ b.i.d. asenapine $(n=106)$; all randomized subjects received one or more doses of the study medication. The study population was $>60 \%$ male, more than half were white, and the average age ranged from 15.2 (asenapine $2.5 \mathrm{mg}$ b.i.d. group) to 15.4 (placebo and asenapine $5 \mathrm{mg}$ b.i.d. groups) years across groups (Table 1). In the 8 week acute phase, similar percentages of adolescents completed the study period across the treatment groups (2.5 mg b.i.d.: $83 \%$; $5 \mathrm{mg}$ b.i.d.: $79 \%$; placebo: $79 \%$ ) (Fig. 1). Mean age at onset of schizophrenia ranged from 13.2 years $(2.5 \mathrm{mg}$ b.i.d. asenapine group) to 13.8 years (placebo group), and most subjects

Table 1. Baseline Demographics: Acute-Phase and OlE Populations (All-Subjects-as-Treated)

\begin{tabular}{|c|c|c|c|c|c|c|}
\hline & \multicolumn{3}{|c|}{8 Week double-blind acute phase } & \multicolumn{3}{|c|}{26 Week $O L E^{\mathrm{a}}$} \\
\hline & $\begin{array}{l}\text { Placebo } \\
(\mathrm{n}=102)\end{array}$ & $\begin{array}{c}\text { Asenapine } \\
2.5 \mathrm{mg} \\
(\mathrm{n}=98)\end{array}$ & $\begin{array}{c}\text { Asenapine } \\
5 \mathrm{mg} \\
(\mathrm{n}=106)\end{array}$ & $\begin{array}{l}\text { Placebo/ } \\
\text { Asenapine } \\
(\mathrm{n}=62)\end{array}$ & $\begin{array}{l}\text { Continuous } \\
\text { asenapine } \\
(\mathrm{n}=134)\end{array}$ & $\begin{array}{c}\text { Total } \\
(\mathrm{n}=196)\end{array}$ \\
\hline \multicolumn{7}{|l|}{ Age (years) } \\
\hline Mean (SD) & $15.4(1.4)$ & $15.2(1.5)$ & $15.4(1.5)$ & $15.4(1.5)$ & $15.3(1.5)$ & $15.3(1.5)$ \\
\hline$\leq 15$ years, $n(\%)$ & $40(39.2)$ & $52(53.1)$ & $45(42.5)$ & $28(45.2)$ & $67(50.0)$ & $95(48.5)$ \\
\hline Male, $n(\%)$ & $62(60.8)$ & $62(63.3)$ & $67(63.2)$ & $37(59.7)$ & $85(63.4)$ & $122(62.2)$ \\
\hline \multicolumn{7}{|l|}{ Race, $n(\%)$} \\
\hline White & $57(55.9)$ & $54(55.1)$ & $55(51.9)$ & $46(74.2)$ & $88(65.7)$ & $134(68.4)$ \\
\hline Black & $6(5.9)$ & $7(7.1)$ & $10(9.4)$ & $1(1.6)$ & $11(8.2)$ & $12(6.1)$ \\
\hline Asian & $34(33.3)$ & 33 (33.7) & $36(34.0)$ & $13(21.0)$ & $28(20.9)$ & $41(20.9)$ \\
\hline Native Hawaiian or Other Pacific Islander & 0 & 0 & $1(0.9)$ & 0 & $1(0.7)$ & $1(0.5)$ \\
\hline Multiracial & $5(4.9)$ & $4(4.1)$ & $4(3.8)$ & $2(3.2)$ & $6(4.5)$ & $8(4.1)$ \\
\hline Weight (kg), mean (SD) & $60.5(6.4)$ & $58.4(15.1)$ & $62.2(16.1)$ & $60.3(16.7)$ & $64.1(16.4)$ & $63.7(16.5)$ \\
\hline BMI $\left(\mathrm{kg} / \mathrm{m}^{2}\right)$, mean $(\mathrm{SD})$ & $21.9(4.9)$ & $21.5(4.7)$ & $22(4.6)$ & $22.3(4.9)$ & $23.1(4.9)$ & $22.9(4.9)$ \\
\hline \multicolumn{7}{|l|}{ Region, $n(\%)$} \\
\hline USA & $14(13.7)$ & $15(15.3)$ & $20(18.9)$ & $6(9.7)$ & $23(17.2)$ & $29(14.8)$ \\
\hline Non-USA & $88(86.3)$ & $83(84.7)$ & $86(81.1)$ & $56(90.3)$ & $111(82.8)$ & $167(85.2)$ \\
\hline
\end{tabular}

${ }^{a}$ Extension-phase characteristics were calculated using the OLE baseline. BMI, body mass index; OLE, open-label extension. 


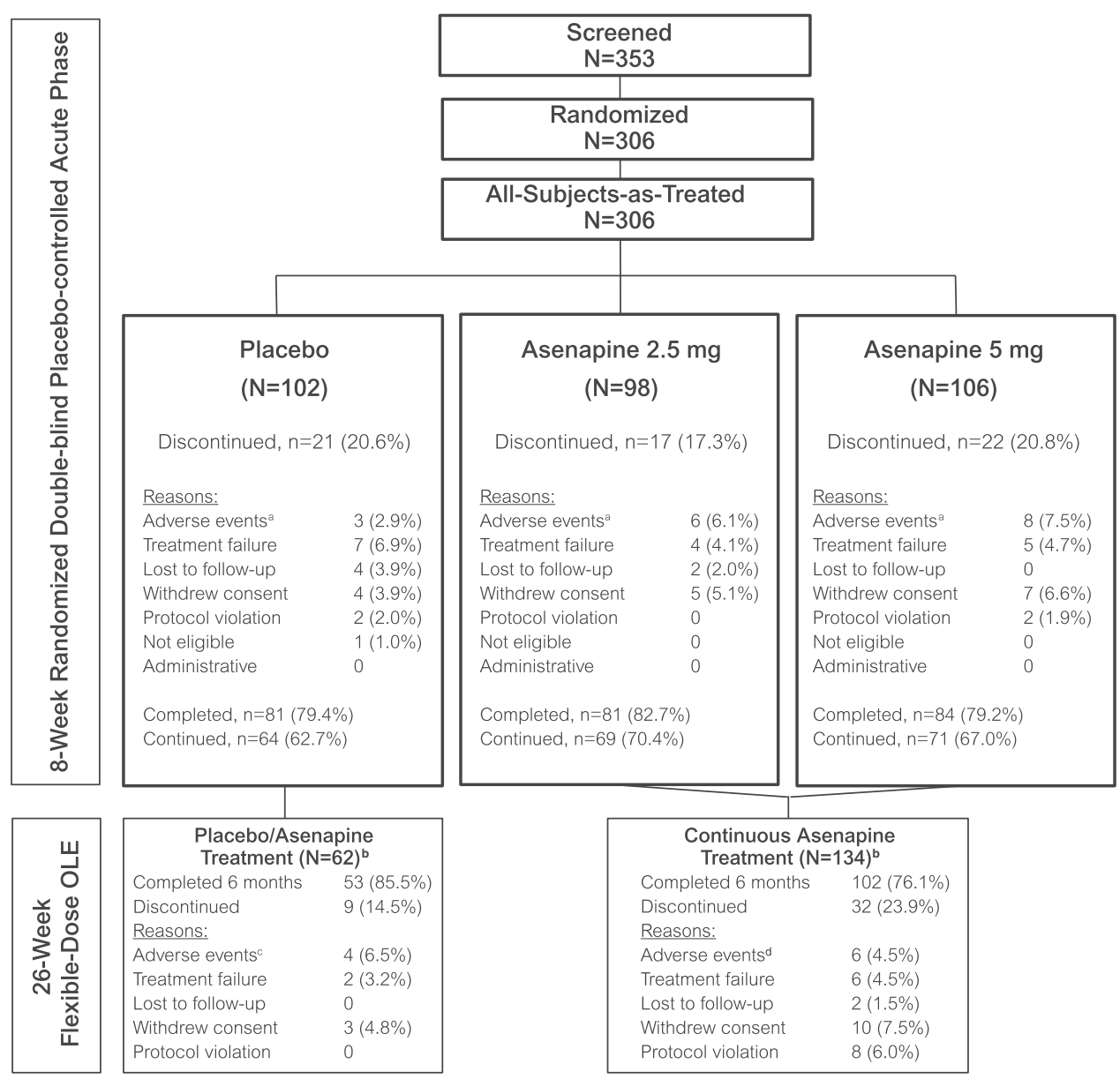

FIG. 1. Subject disposition. ${ }^{\mathrm{a}}$ Of the AEs in the 8 week acute phase, three in patients randomized to placebo, three in patients randomized to asenapine $2.5 \mathrm{mg}$, and four in patients randomized to asenapine $5 \mathrm{mg}$ were caused by the disease under study. ${ }^{\mathrm{b}}$ The analysis population included all randomized subjects $<18$ years of age who received one osr more dose of trial medication; eight subjects (two in the placebo/asenapine group and six in the asenapine/asenapine group) who were 18 year old entered and were treated in the OLE but were not included in the primary analysis. ${ }^{c}$ Three of the AEs in the placebo/asenapine group in the OLE were caused by the disease under study. ${ }^{\mathrm{d}}$ Four of the AEs in the continuous asenapine group in the OLE were caused by the disease under study. AE, adverse event; OLE, open-label extension.

were diagnosed with schizophrenia of the paranoid type (DSM-IVTR 295.30) (Table 2). Less than $10 \%$ of the population had a history of Axis I disorders other than schizophrenia or Axis II disorders, and $>60 \%$ of subjects had received antipsychotic medication previously (Table 2). The FAS for efficacy analysis excluded 6 of the 306 subjects who were randomized and treated but did not have a postbaseline PANSS assessment ( 2 from each treatment group; $n=100$ for placebo, $n=96$ for $2.5 \mathrm{mg}$ b.i.d. asenapine, and $n=104$ for $5 \mathrm{mg}$ b.i.d. asenapine).

Twenty-six week OLE. Most (83\%) of the subjects who completed the acute phase enrolled in the OLE. A total of 196 adolescents $<18$ years of age enrolled and were treated with flexible-dose asenapine in the extension phase. Of these, $62 \mathrm{had}$ been treated with placebo (hereafter referred to as the placebo/ asenapine group) and 134 with asenapine (either $2.5 \mathrm{mg}$ b.i.d. or $5 \mathrm{mg}$ b.i.d.; hereafter referred to as the continuous asenapine group) in the antecedent acute phase. The FAS population in the OLE consisted of 193 subjects, excluding 3 additional subjects in the continuous asenapine group who discontinued the OLE before having an open-label PANSS assessment. The demographics of adolescents who participated in the OLE were similar to those who participated in the acute phase (Table 1). A greater percentage of adolescents previously treated with placebo completed the OLE compared with those continuously treated with asenapine (85\% vs. $76 \%$, respectively) (Fig. 1). The mean average daily dose of asenapine in the OLE was $8.7 \mathrm{mg} /$ day (median average daily dose $9.8 \mathrm{mg}$; modal average daily dose $9.9 \mathrm{mg}$ ).

\section{Efficacy}

Eight week acute phase. In the MMRM analysis of the PANSS total score change from baseline to day 56, the primary objective was not met because the difference from placebo was not statistically significant for either asenapine group. The difference in least squares (LS) mean change from baseline to day 56 in the PANSS total score was -4.8 (unadjusted $95 \%$ confidence interval $[\mathrm{CI}],-9.9$ to 0.4 ; adjusted $p=0.070$ ) for $2.5 \mathrm{mg}$ asenapine b.i.d. versus placebo and -5.6 (unadjusted $95 \% \mathrm{CI},-10.7$ to -0.5 ; adjusted $p=0.064$ ) for $5 \mathrm{mg}$ asenapine b.i.d. versus placebo (Fig. 2A). Based on unadjusted $p$ values relative to placebo, the LS mean change from baseline in PANSS total score over time was 
Table 2. Schizophrenia Characteristics at Acute-Phase Baseline (All-Subjects-AS-Treated)

\begin{tabular}{|c|c|c|c|}
\hline Characteristic & $\begin{array}{l}\text { Placebo } \\
(\mathrm{n}=102)\end{array}$ & $\begin{array}{c}\text { Asenapine } \\
2.5 \mathrm{mg} \\
(\mathrm{n}=98)\end{array}$ & $\begin{array}{c}\text { Asenapine } \\
5 \mathrm{mg} \\
(\mathrm{n}=106)\end{array}$ \\
\hline $\begin{array}{l}\text { Age of onset (years), } \\
\text { mean (SD) }\end{array}$ & $13.8(2.2)$ & $13.2(2.7)$ & $13.4(2.7)$ \\
\hline \multicolumn{4}{|c|}{ Current DSM-IV-TR diagnosis, $n(\%)$} \\
\hline Paranoid $(295.30)$ & $74(72.5)$ & $82(83.7)$ & $85(80.2)$ \\
\hline Disorganized (295.10) & $6(5.9)$ & $5(5.1)$ & $10(9.4)$ \\
\hline Undifferentiated (295.90) & $22(21.6)$ & $11(11.2)$ & $11(10.4)$ \\
\hline $\begin{array}{l}\text { History of } \geq 1 \text { Axis I/II } \\
\text { disorders other than } \\
\text { schizophrenia, } n(\%)\end{array}$ & $10(9.8)$ & $9(9.2)$ & $7(6.6)$ \\
\hline $\begin{array}{l}\text { Prior antipsychotic } \\
\quad \text { medication use, } n(\%)\end{array}$ & $65(63.7)$ & $71(72.4)$ & $71(67.0)$ \\
\hline Atypical & $53(52.0)$ & $55(56.1)$ & $54(50.9)$ \\
\hline Typical & $19(18.6)$ & $23(23.5)$ & $25(23.6)$ \\
\hline $\begin{array}{l}\text { Baseline PANSS total } \\
\text { score, mean }(\mathrm{SD})^{\mathrm{a}}\end{array}$ & $97.5(10.3)$ & $97.4(10.2)$ & $98.6(13.4)$ \\
\hline $\begin{array}{l}\text { Baseline CGI-S } \\
\text { score, mean SD }\end{array}$ & $4.6(0.6)$ & $4.6(0.6)$ & $4.7(0.6)$ \\
\hline
\end{tabular}

${ }^{a} n=100$ for placebo, $n=96$ for asenapine $2.5 \mathrm{mg}$ b.i.d., $n=104$ for asenapine $5 \mathrm{mg}$ b.i.d.

CGI-S, Clinical Global Impressions-Severity; DSM-IV-TR, Diagnostic and Statistical Manual of Mental Disorders, 4th ed., Text Revision: PANSS, Positive and Negative Syndrome Scale.

significantly greater for the $2.5 \mathrm{mg}$ b.i.d. asenapine group on days 21,28 , and 42 and for the $5 \mathrm{mg}$ b.i.d. asenapine group on days 28 , 42, and 56 (Fig. 2B). On the key secondary outcome, which can be considered only exploratory because the primary efficacy objective was not met, a significant improvement in the CGI-S score was observed in the $5 \mathrm{mg}$ b.i.d. group when compared with placebo on day 56 (unadjusted LS mean [95\% CI] $-0.3[-0.6,-0.0]$ ); (unadjusted $p=0.024$ ) (Fig. 2C) but not for the $2.5 \mathrm{mg}$ b.i.d. group.

Other planned exploratory end-points of interest included PANSS 30\% responders, PANSS subscale scores, and treatment by region interaction. The $p$ value for treatment by region interaction (United States vs. non-United States) in the MMRM for change from baseline in PANSS total score analysis at day 56 was 0.646 , suggesting that the treatment effect at day 56 of asenapine compared with placebo was not significantly different for subjects in the United States and not in the United States. In this subgroup analysis, the LS mean changes in PANSS total score on day 56 in the United States $(n=48,-3.7$ for $2.5 \mathrm{mg}$ b.i.d. vs. placebo and -12.0 for $5 \mathrm{mg}$ b.i.d. vs placebo) and not in the United States $(n=252$, -5.0 for $2.5 \mathrm{mg}$ b.i.d. vs. placebo and -4.6 for $5 \mathrm{mg}$ b.i.d. vs. placebo) were comparable with the overall treatment differences observed in the primary efficacy analysis, with the exception of United States subjects in the $2.5 \mathrm{mg}$ b.i.d. asenapine group, which could be explained by the imbalance in the sample size.

Based on unadjusted $p$ values, both asenapine dose groups had a higher PANSS $30 \%$ responder rate $(50 \%$ for asenapine $2.5 \mathrm{mg}$ b.i.d., $p=0.028 ; 49 \%$ for asenapine $5 \mathrm{mg}$ b.i.d., $p=0.048)$ than placebo (36\% of subjects) at day 56 . The average change from baseline in the PANSS Positive Subscale Score indicated consistently larger improvement for the asenapine treatment groups relative to placebo starting at day 7. Differences in LS mean changes from baseline to day 56 on the PANSS Positive Subscale were - 1.6 for asenapine $2.5 \mathrm{mg}$ b.i.d. (unadjusted $p=0.067$ ) and -2.1 for asenapine $5 \mathrm{mg}$ b.i.d. (unadjusted $p$ value of 0.012 ). Differences in
LS mean changes from baseline to day 56 on the PANSS Negative Subscale were -1.2 for both asenapine groups versus placebo (unadjusted $p$ values of 0.097 and 0.099 , respectively).

Twenty-six week OLE. At baseline in the OLE, mean PANSS total scores were 78.9 for the placebo/asenapine group $(n=62)$ and 72.8 for the continuous asenapine group $(n=131)$; baseline mean CGI-S scores were 3.7 and 3.5, respectively. On average, numerical improvements for the PANSS total and CGI-S scores in the acute phase were maintained and continued to indicate improvement over the course of 26 weeks of flexible-dose asenapine treatment. Using an $\mathrm{OC}$ analysis, the mean change from the OLE baseline to week in the OLE was -16.1 points for the placebo/asenapine group and -11.2 points for the continuous asenapine group (Fig. 3A). Overall, $48 \%$ of subjects in the OLE had a $30 \%$ decrease from OLE baseline to end-point PANSS total score (56\% in the placebo/asenapine group and $43 \%$ in the continuous asenapine group). When change in PANSS total score was calculated from the acute phase baseline (including 18-year-olds) to the end of the OLE, representing 34 weeks of asenapine treatment for subjects in the continuous asenapine group, the mean changes were -36.7 points for the continuous asenapine group and -34.4 for the placebo/asenapine group. Of the 103 adolescents who were PANSS $30 \%$ responders at the end of the acute phase and who continued in the OLE, a cumulative percentage of $79 \%$ (76\% in the placebo/ asenapine group and $80 \%$ in the continuous asenapine group) maintained this effect. The mean change in CGI-S from the OLE baseline to OLE Week 26 was -1.1 points for the placebo/asenapine group and -0.7 for the continuous asenapine group (Fig 3B).

\section{Safety}

Eight week acute phase. The mean duration of treatment was 49 days for placebo, 54 days for $2.5 \mathrm{mg}$ b.i.d. asenapine, and 49 days for $5 \mathrm{mg}$ b.i.d. asenapine. No deaths occurred during the acute phase, and no subjects had a TEAE of attempted suicide or C-SSRS scores indicating suicidal intent with a formal plan or actual suicidal behaviors. The percentages of subjects experiencing SAEs were similar across the groups (placebo, 2.9\%; asenapine $2.5 \mathrm{mg}$ b.i.d., 3.1\%; asenapine $5 \mathrm{mg}$ b.i.d., 2.8\%) (Table 3), the most common of which was worsening schizophrenia. The DMC requested that treatment be unblinded for five subjects who experienced serious, unexpected (per the Reference Safety Information in the asenapine Investigator Brochure) AEs that the investigator deemed to be related to study drug or trial procedure. Three of these five subjects were randomized to placebo, and each placebo-treated subject was hospitalized for worsening schizophrenia and study medication was discontinued (days 17, 27, and 56 of treatment). One subject randomized to $5 \mathrm{mg}$ b.i.d. asenapine was hospitalized for worsening of schizophrenia; study medication was continued, and the subject received additional medication and therapeutic procedures. One subject randomized to $2.5 \mathrm{mg}$ b.i.d. asenapine was hospitalized for hallucination (auditory) on day 3 , and study medication was discontinued. Of the six $(6 \%)$ subjects in the asenapine $2.5 \mathrm{mg}$ b.i.d. group who discontinued, one subject each discontinued because of schizophrenia, agitation, depression, auditory hallucination, somnolence, and pneumonia. A total of eight (8\%) subjects in the asenapine $5 \mathrm{mg}$ b.i.d. group discontinued; the most common reason was worsening schizophrenia (three subjects) followed by insomnia and akathisia (one subject), dysgeusia (one subject), sedation (one subject), and polycythemia (one subject), and abnormal alanine aminotransferase (one subject). An accidental 

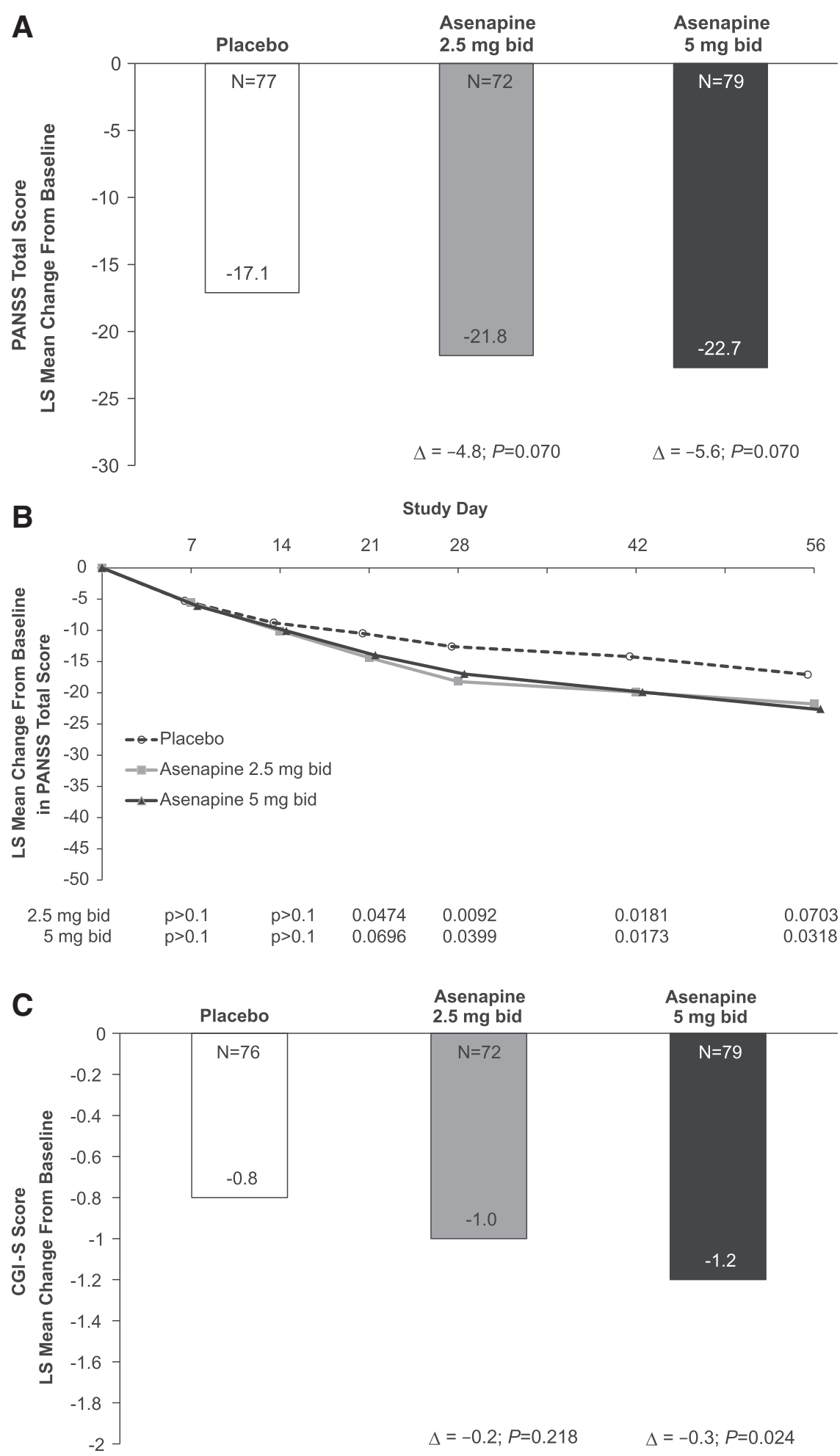

FIG. 2. Efficacy during the acute phase (MMRM, full analysis set). (A) LS mean change from baseline in PANSS total score at day 56 of treatment. $P$ values were adjusted using the Hochberg procedure. $\Delta=$ asenapine minus placebo. (B) LS mean change from baseline (with 95\% CI) in PANSS total score by visit. Unadjusted $p$ values for treatment comparisons with placebo. (C) LS mean change from baseline in CGI-S score at day 56 of treatment. Unadjusted $p$ values for treatment comparisons with placebo. $\Delta=$ asenapine minus placebo. CGI-S, Clinical Global Impressions-Severity; CI, confidence interval; LS, least squares; MMRM, mixed model for repeated measures; PANSS, Positive and Negative Syndrome Scale. 
A

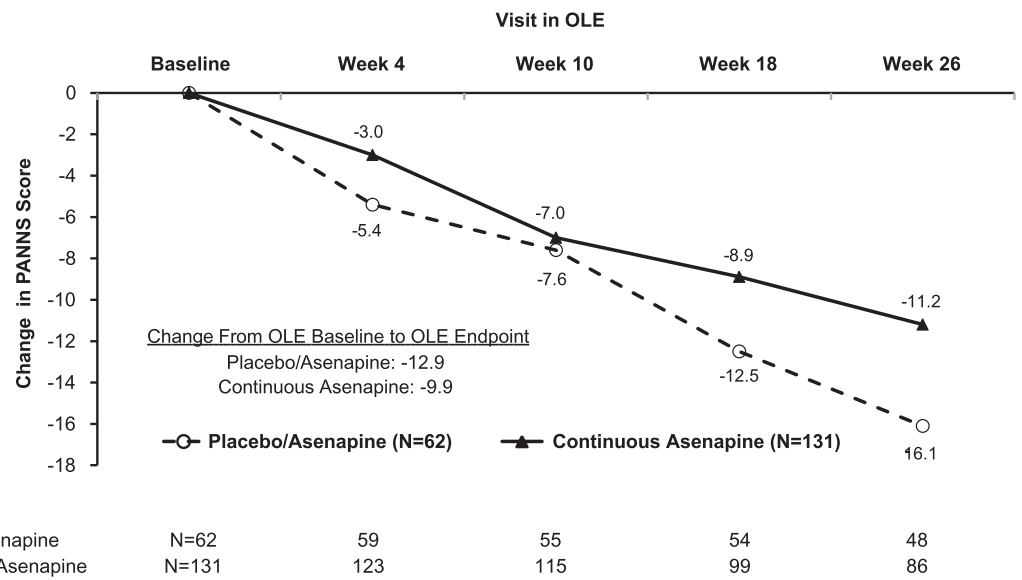

$\mathbf{B}$

Visit in OLE

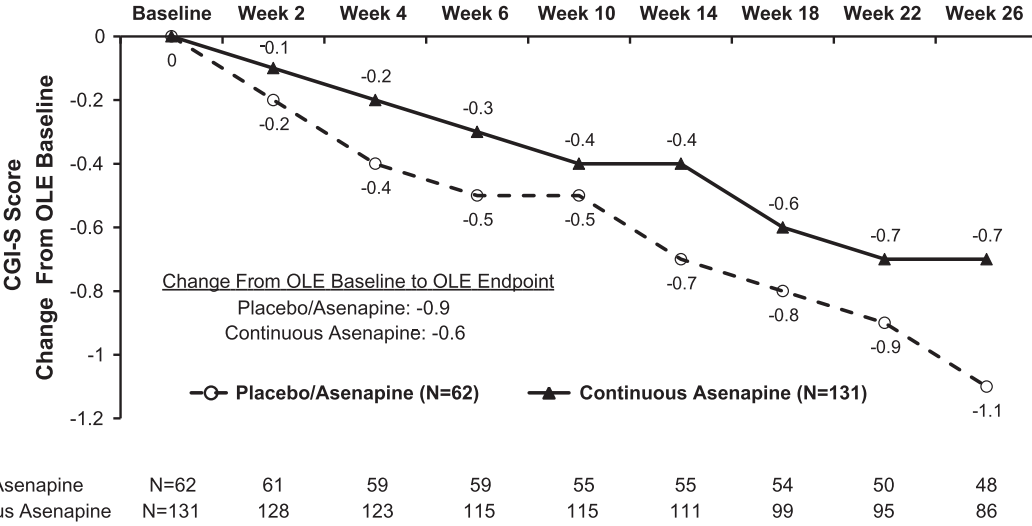

FIG. 3. Efficacy during the OLE (OC, full analysis set). (A) Mean change in PANSS total score from open-label baseline to end of OLE by visit. (B) Mean (SD) change in CGI-S score from open-label baseline to end of OLE by visit. CGI-S, Clinical Global ImpressionsSeverity; OC, observed cases; OLE, open-label extension; PANSS, Positive and Negative Syndrome Scale.

overdose in a subject who took one extra dose of asenapine $2.5 \mathrm{mg}$ was reported, with no untoward consequences. There were no reports of drug abuse during the acute phase.

The overall incidence of TEAEs was $47 \%$ in the placebo group, $62 \%$ in the $2.5 \mathrm{mg}$ b.i.d. asenapine group, and $67 \%$ in the $5 \mathrm{mg}$ b.i.d. asenapine group (Table 3). Nervous system AEs were the most common overall, experienced by $14 \%$ of subjects in the placebo group, $37 \%$ in the asenapine $2.5 \mathrm{mg}$ b.i.d. group, and $48 \%$ in the asenapine $5 \mathrm{mg}$ b.i.d. group (Table 3). Among the preselected TEAEs of interest, the composite safety end-point of somnolence, sedation, and hypersomnia combined were significantly more frequent in both asenapine groups $(2.5 \mathrm{mg}$ b.i.d.: $24 \%, p<0.05 ; 5 \mathrm{mg}$ b.i.d.: $29 \%, p<0.05)$ compared with placebo $(9 \%)$ (Table 3). Compared with placebo, dizziness was significantly more frequent in the $2.5 \mathrm{mg}$ b.i.d. group (7\% vs. $1 \%$ ), whereas akathisia (7\% vs. $1 \%$ ) occurred more frequently in the $5 \mathrm{mg}$ b.i.d. group than in the placebo group. The occurrence of EPS, as identified by the MedDRA SMQ (narrow), was numerically greater in both asenapine groups than in the placebo group. More subjects in the asenapine $5 \mathrm{mg}$ b.i.d. group (11\%) reported concomitant medication use corresponding to an EPS AE compared with the placebo (3\%) and asenapine $2.5 \mathrm{mg}$ b.i.d. groups (2\%). Clinically significant weight gain (increase of $\geq 7 \%$ from baseline to end-point) was more frequent in the $2.5 \mathrm{mg}(9 \% ; p>0.05)$ and $5 \mathrm{mg}(13 \% ; p<0.05)$ b.i.d. groups than in the placebo group (3\%). Mean weight changes from baseline were $0.1 \mathrm{~kg}$ for placebo, $1.3 \mathrm{~kg}$ for asenapine $2.5 \mathrm{mg}$ b.i.d., and $1.4 \mathrm{~kg}$ for asenapine $5 \mathrm{mg}$ b.i.d. After correcting for growth by age and sex, $Z$ scores for weight and BMI confirmed a clinically meaningful increase in weight for the asenapine 2.5 and $5 \mathrm{mg}$ b.i.d. groups compared with placebo (Table 4).

With respect to laboratory parameters of interest, the mean change from baseline to end-point in fasting insulin was greater for the asenapine $2.5 \mathrm{mg}$ b.i.d. and $5 \mathrm{mg}$ b.i.d. groups compared with placebo, with an apparent dose-response for asenapine (Table 5). Potential new-onset diabetes per the MedDRA hyperglycemia/new onset diabetes mellitus SMQ (broad) was reported in four $(4 \%)$ placebo-treated subjects, seven (7\%) $2.5 \mathrm{mg}$ b.i.d. asenapine-treated subjects, and seven (7\%) $5 \mathrm{mg}$ b.i.d. asenapine-treated subjects; and three asenapine-treated subjects (one in the $2.5 \mathrm{mg}$ bid group and two in the $5 \mathrm{mg}$ bid group) met the IDF criteria for new-onset metabolic syndrome. No notable treatment-group differences were observed for fasting cholesterol, fasting glucose, fasting triglycerides, or HbA1c (Table 5). Although mean changes in prolactin were similar between groups, prolactin concentrations $\geq 1.1$ times the upper limit of normal were more common in the asenapine groups ( $23 \%$ for $2.5 \mathrm{mg}$ b.i.d., $19 \%$ for $5 \mathrm{mg}$ b.i.d.) compared with placebo $(13 \%)$ with no apparent dose response. One subject in the asenapine $2.5 \mathrm{mg}$ bid group had QTc prolongation $\geq 500 \mathrm{msec}$ per Bazett but not QTc Fridericia criteria, and had no electrocardiogram-related TEAEs. Rates of orthostatic hypotension (supine to standing), defined as $>20 \mathrm{~mm} \mathrm{Hg}$ decrease in systolic blood pressure or $>10 \mathrm{~mm} \mathrm{Hg}$ decrease in diastolic blood pressure were similar 
Table 3. Summary of Selected TeAEs of Interest in Adolescents with Schizophrenia

\begin{tabular}{|c|c|c|c|c|c|c|}
\hline & \multicolumn{3}{|c|}{8 Week acute phase } & \multicolumn{3}{|c|}{26 Week $O L E^{\mathrm{a}}$} \\
\hline & $\begin{array}{l}\text { Placebo } \\
(\mathrm{n}=102)\end{array}$ & $\begin{array}{c}\text { Asenapine } \\
2.5 \mathrm{mg} \text { b.i.d. } \\
(\mathrm{n}=98)\end{array}$ & $\begin{array}{l}\text { Asenapine } \\
5 \mathrm{mg} \text { b.i.d. } \\
(\mathrm{n}=106)\end{array}$ & $\begin{array}{l}\text { Placebo/ } \\
\text { Asenapine } \\
(\mathrm{n}=62)\end{array}$ & $\begin{array}{c}\text { Continuous } \\
\text { Asenapine } \\
(\mathrm{n}=134)\end{array}$ & $\begin{array}{c}\text { Total } \\
(\mathrm{n}=196)\end{array}$ \\
\hline Any TEAE, $n(\%)^{\mathrm{b}}$ & $48(47.1)$ & $61(62.2)$ & $71(67.0)$ & $39(62.9)$ & $75(56.0)$ & $114(58.2)$ \\
\hline Death & 0 & 0 & 0 & $1(1.6)$ & 0 & $1(0.5)$ \\
\hline SAE & $3(2.9)$ & $3(3.1)$ & $3(2.8)$ & $2(3.2)$ & $5(3.7)$ & $7(3.6)$ \\
\hline Discontinuation caused by $\mathrm{AE}$ & $3(2.9)$ & $6(6.1)$ & $8(7.5)$ & $4(6.5)$ & $6(4.5)$ & $10(5.1)$ \\
\hline \multicolumn{7}{|l|}{ Most common TEAEs ${ }^{\mathrm{b}, \mathrm{c}}$} \\
\hline Nervous system disorders & $14(13.7)$ & $36(36.7)$ & $51(48.1)$ & $30(48.4)$ & $39(29.1)$ & $69(35.2)$ \\
\hline Somnolence & $7(6.9)$ & $20(20.4)$ & $18(17.0)$ & $14(22.6)$ & $15(11.2)$ & $29(14.8)$ \\
\hline Sedation & $2(2.0)$ & $4(4.1)$ & $12(11.3)$ & $2(3.2)$ & $8(6.0)$ & $10(5.1)$ \\
\hline Gastrointestinal disorders & $15(14.7)$ & $16(16.3)$ & $15(14.2)$ & $8(12.9)$ & $10(7.5)$ & $18(9.2)$ \\
\hline Hypoesthesia oral & $1(1.0)$ & $5(5.1)$ & $5(4.7)$ & $5(8.1)$ & $1(0.7)$ & $6(3.1)$ \\
\hline Respiratory, thoracic, and mediastinal disorders & $2(2.0)$ & $5(5.1)$ & $3(2.8)$ & $3(4.8)$ & $5(3.7)$ & $8(4.1)$ \\
\hline$\geq 1 \mathrm{AE}$ of interest during the study ${ }^{\mathrm{b}}$ & $19(18.6)$ & $36(36.7)$ & $49(46.2)$ & $31(50.0)$ & $33(24.6)$ & $64(32.7)$ \\
\hline Akathisia & $1(1.0)$ & $4(4.1)$ & $7(6.6)^{d}$ & $2(3.2)$ & $2(1.5)$ & $4(2.0)$ \\
\hline Dizziness & $1(1.0)$ & $7(7.1)^{\mathrm{d}}$ & $2(1.9)$ & $3(4.8)$ & $3(2.2)$ & $6(3.1)$ \\
\hline Hypoesthesia oral, dysgeusia combined & $3(2.9)$ & $6(6.1)$ & $8(7.5)$ & $6(9.7)$ & $1(0.7)$ & $7(3.6)$ \\
\hline Insomnia & $6(5.9)$ & $5(5.1)$ & $10(9.4)$ & $3(4.8)$ & $5(3.7)$ & $8(4.1)$ \\
\hline EPS (narrow) ${ }^{\mathrm{e}}$ & $4(3.9)$ & $5(5.1)$ & $11(10.4)$ & $6(9.7)$ & $3(2.2)$ & $9(4.6)$ \\
\hline Somnolence, sedation, hypersomnia combined & $9(8.8)$ & $24(24.5)^{\mathrm{d}}$ & $31(29.2)^{\mathrm{d}}$ & $17(27.4)$ & $25(18.7)$ & $42(21.4)$ \\
\hline Weight gain $\geq 7 \%$ from baseline to end-point ${ }^{\mathrm{f}}$ & $3 / 98(3.1)$ & $9 / 95(9.5)$ & $10 / 99(10.1)^{d}$ & $8(12.9)$ & $20(14.9)$ & $28(14.3)$ \\
\hline
\end{tabular}

${ }^{\mathrm{a}}$ For the OLE, TEAEs were counted from the open-label baseline; TEAEs in the OLE were newly reported in the OLE or worsened in severity during the OLE compared with the acute phase.

${ }^{\mathrm{b}}$ Every adolescent was counted a single time for each applicable row and column.

${ }^{\mathrm{c}}$ Incidence $\geq 5 \%$ in either asenapine group and more than twice that with placebo and not summarized as an AE of interest.

${ }^{\mathrm{d}} p<0.05$ for placebo vs asenapine using Miettinen and Nurminen (1985).

${ }^{e}$ EPS (narrow) indicates that preferred terms in the SMQ (akathisia, dyskinesia, dystonia, and Parkinson-like events) were highly likely to be associated with EPS.

${ }^{\mathrm{f}}$ Adolescents with at least one postbaseline weight value were included; baseline for OLE analysis was the open-label baseline.

AE, adverse event; EPS, extrapyramidal symptoms; OLE, open-label extension; SAE, serious adverse event; SMQ, Standardized Medical Dictionary for Regulatory Activities (MedDRA) Query; TEAE, treatment-emergent adverse event.

across treatment groups ( $9 \%$, placebo; $4 \%$, asenapine $2.5 \mathrm{mg}$ b.i.d.; $8 \%$, asenapine $5 \mathrm{mg}$ b.i.d.) during the acute phase.

Twenty-six week OLE. The mean duration of asenapine treatment in the OLE was 171 days for placebo/asenapine and 163 days for continuous asenapine, with a mean average daily dose of $9.8 \mathrm{mg}$ for both groups. One death occurred during the OLE (placebo/asenapine), secondary to a fall from a sixth floor window. This event was determined by the investigator and the subject's family to be accidental, because the study participant had no history of suicidal ideation, suicide attempt, or deliberate self-harm before or during the trial. SAEs, including the one death, were reported for seven $(4 \%)$ subjects in the total OLE population (two placebo/ asenapine, five continuous asenapine) (Table 3). Hospitalizations related to psychiatric disorders occurred for one subject in the placebo/asenapine group (aggression and anxiety) and five in the continuous asenapine group (three worsening of schizophrenia, one aggression, and one agitation). Ten (5\%; four placebo/asenapine, six continuous asenapine) subjects discontinued owing to AEs, four of which were SAEs. Eight subjects (4\%) in the total population reported suicidal ideation on the C-SSRS during the OLE phase, none of which included intent with a formal plan or actual suicidal

Table 4. $Z$ Scores for Weight and BMI (All-Subjects-as-Treated)

\begin{tabular}{|c|c|c|c|c|c|c|}
\hline \multirow[b]{2}{*}{$\begin{array}{l}\mathrm{Z} \text { score for age } \\
\text { and sex }(\text { mean } \pm S D)\end{array}$} & \multicolumn{3}{|c|}{8 Week acute phase } & \multicolumn{3}{|c|}{26 Week $O L E^{\mathrm{a}}$} \\
\hline & $\begin{array}{l}\text { Placebo } \\
(\mathrm{n}=98)\end{array}$ & $\begin{array}{c}\text { Asenapine } \\
2.5 \mathrm{mg} \text { b.i.d. }(\mathrm{n}=95)\end{array}$ & $\begin{array}{c}\text { Asenapine } \\
5 \mathrm{mg} \text { b.i.d. }(\mathrm{n}=99)\end{array}$ & $\begin{array}{c}\text { Placebo/ } \\
\text { Asenapine }(\mathrm{n}=62)\end{array}$ & $\begin{array}{c}\text { Continuous } \\
\text { asenapine }(\mathrm{n}=134)\end{array}$ & $\begin{array}{c}\text { Total } \\
(\mathrm{n}=196)\end{array}$ \\
\hline \multicolumn{7}{|l|}{ Weight (kg) } \\
\hline Baseline & $-0.05 \pm 1.46$ & $-0.13 \pm 1.48$ & $0.20 \pm 1.29$ & $0.21 \pm 1.31$ & $0.37 \pm 1.27$ & $0.32 \pm 1.28$ \\
\hline End-point & $-0.07 \pm 1.44$ & $-0.05 \pm 1.46$ & $0.26 \pm 1.30$ & $0.23 \pm 1.32$ & $0.35 \pm 1.24$ & $0.31 \pm 1.26$ \\
\hline Change $^{\mathrm{a}}$ & $-0.02 \pm 0.24$ & $0.09 \pm 0.21$ & $0.06 \pm(0.20)$ & $0.01 \pm 0.21$ & $-0.02 \pm 0.27$ & $-0.01 \pm 0.25$ \\
\hline \multicolumn{7}{|l|}{ BMI $\left(\mathrm{kg} / \mathrm{m}^{2}\right)$} \\
\hline Baseline & $0.09 \pm 1.26$ & $0.03 \pm 1.31$ & $0.32 \pm 1.10$ & $0.24 \pm 1.17$ & $0.47 \pm 1.13$ & $0.40 \pm 1.14$ \\
\hline End-point & $0.05 \pm 1.29$ & $0.14 \pm 1.29$ & $0.40 \pm 1.09$ & $0.26 \pm 1.16$ & $0.46 \pm 1.11$ & $0.39 \pm 1.13$ \\
\hline Change $^{\mathrm{a}}$ & $-0.04 \pm 0.30$ & $0.11 \pm 0.24$ & $0.08 \pm 0.24$ & $0.02 \pm 0.33$ & $-0.02 \pm 0.31$ & $-0.01 \pm 0.31$ \\
\hline
\end{tabular}

${ }^{\mathrm{a}}$ For the OLE, change from baseline to end-point was calculated using the open-label baseline.

BMI, body mass index; OLE, open-label extension. 
Table 5. Mean Change $( \pm$ SD) from Baseline in Laboratory Parameters of Interest

\begin{tabular}{|c|c|c|c|c|c|c|}
\hline & \multicolumn{3}{|c|}{8 Week (double-blind) acute phase } & \multicolumn{3}{|c|}{26 week $O L E^{\mathrm{a}}$} \\
\hline & $\begin{array}{l}\text { Placebo } \\
(\mathrm{n}=102)\end{array}$ & $\begin{array}{c}\text { Asenapine } \\
2.5 \mathrm{mg} \\
(\mathrm{n}=98)\end{array}$ & $\begin{array}{c}\text { Asenapine } \\
5 \mathrm{mg} \\
(\mathrm{n}=106)\end{array}$ & $\begin{array}{l}\text { Placebo/ } \\
\text { Asenapine } \\
(\mathrm{n}=62)\end{array}$ & $\begin{array}{c}\text { Asenapinel } \\
\text { Asenapine } \\
(\mathrm{n}=134)\end{array}$ & $\begin{array}{c}\text { Total } \\
(\mathrm{n}=196)\end{array}$ \\
\hline Fasting cholesterol (mmol/L) & $-0.31 \pm 0.62$ & $-0.05 \pm 0.79$ & $-0.09 \pm 0.64$ & $0.06 \pm 0.62$ & $-0.05 \pm 0.58$ & $-0.02 \pm 0.59$ \\
\hline Fasting triglycerides $(\mathrm{mmol} / \mathrm{L})$ & $-0.11 \pm 0.87$ & $-0.01 \pm 0.69$ & $-0.02 \pm 0.76$ & $0.05 \pm 0.40$ & $-0.02 \pm 0.58$ & $0.01 \pm 0.52$ \\
\hline Fasting glucose $(\mathrm{mmol} / \mathrm{L})$ & $-0.14 \pm 0.60$ & $-0.01 \pm 0.72$ & $0.12 \pm 0.69$ & $0.19 \pm 0.75$ & $-0.02 \pm 0.83$ & $0.05 \pm 0.81$ \\
\hline Hemoglobin A1c $(<7.0 \% \text { to } \geq 7.0 \%)^{b}$ & 0 & 0 & 0 & 0 & $1(0.8)$ & $1(0.5)$ \\
\hline Fasting insulin (pmol/L) & $-2.86 \pm 102.54$ & $15.67 \pm 5244$ & $34.98 \pm 76.92$ & $16.93 \pm 81.27$ & $1.28 \pm 99.09$ & $6.43 \pm 93.64$ \\
\hline Prolactin $(\mu \mathrm{g} / \mathrm{L})$ & $-9.10 \pm 23.62$ & $-9.09 \pm 28.92$ & $-10.04 \pm 26.64$ & $5.27 \pm 19.23$ & $2.92 \pm 23.7$ & $3.69 \pm 22.33$ \\
\hline
\end{tabular}

${ }^{\mathrm{a}}$ For the extension phase, mean changes and shifts were calculated using the open-label extension baseline.

${ }^{\mathrm{b}}$ Number $(\%)$ of adolescents with a shift in hemoglobin A1c outside the predefined limits of change during the treatment phase.

OLE, open-label extension.

behaviors; four of the eight subjects had a history of suicidal ideation/behavior prior to participation in the acute trial. A TEAE of suicidal ideation was associated with three $(1.5 \%)$ of these events, but no TEAEs of suicidal behavior or suicide attempt were reported. Parental consent was withdrawn for the six subjects with suicidal ideation. Four accidental overdoses, defined per protocol as any day in which a subject took $\geq 10 \mathrm{mg}$ of asenapine, were reported during the OLE. One of these overdoses was reported with a TEAE of sedation; this subject's mother gave him a total of four extra tablets of asenapine $5 \mathrm{mg}$ during a six day period (verbatim term for this event was accidental overdose without AE). The DMC had no specific safety concerns during the OLE.

Consistent with the acute phase, the composite end-point of somnolence, sedation, and hypersomnia was the most frequently reported TEAE of interest in the OLE (27\% in the placebo/asenapine and $19 \%$ in the continuous asenapine group Table 3 ). With the exception of the TEAE of $\geq 7 \%$ weight gain, which was reported with similar frequency between the OLE groups (13\% in the placebo/asenapine group and $15 \%$ in the continuous asenapine group), the placebo/asenapine group had a greater frequency of all other TEAEs of interest in the OLE compared with the continuous asenapine group (Table 3). Overall mean weight gain from OLE baseline to end-point was $1.6 \mathrm{~kg}$ for the placebo/asenapine group and $1.0 \mathrm{~kg}$ for the continuous asenapine group. $Z$ scores for weight and BMI, adjusting for growth based on age and sex and calculated from OLE baseline (Table 4), as well as weight and BMI percentiles overtime (Figs. S2 and S3) (see online supplementary material at http://www.liebertonline.com/jcap), suggested that the weight increase following initiation of asenapine in the acute phase appeared to stabilize over the course of the OLE. Categorical BMI shifts from OLE baseline are provided in Table S1 (see online supplementary material at http://www.liebertonline.com/jcap).

Mean changes from baseline to end-point in metabolic chemistry parameter levels in the total treatment group were generally modest in number (Table 5). Eight (4\%) subjects met the criteria for new onset hyperglycemia/diabetes mellitus (SMQ [broad]), of which five in the continuous asenapine group also met the $\geq 7 \%$ weight gain criterion. New-onset metabolic syndrome per IDF criteria was met by seven subjects during the OLE, two in the placebo/asenapine group and five in the continuous asenapine group. Although mean change in prolactin from baseline to end-point was small $(3.7 \mu \mathrm{g} / \mathrm{L})$ during the OLE, prolactin concentrations $\geq 1.1$ times the upper limit of normal were reported for $32 \%$ of subjects in the placebo/asenapine group and $31 \%$ in the continuous asenapine group. One adolescent had hyperprolactinemia (prolactin concen- tration of $146 \mu \mathrm{g} / \mathrm{L})$, breast engorgement, and hyperinsulinemia (insulin $295.86 \mathrm{pmol} / \mathrm{L}$ ) on day 188 . Another adolescent had irregular menstruation (prolactin concentration of $30.3 \mu \mathrm{g} / \mathrm{L}$ at baseline). This TEAE resolved on day 165 (no laboratory data available), and prolactin was normal $(19.2 \mu \mathrm{g} / \mathrm{L})$ on trial Day 129 but again was elevated $(40 \mu \mathrm{g} / \mathrm{L})$ on day 173 without further followup available.

\section{Discussion}

Although improvements in PANSS total score during the 8 week acute phase were numerically greater for asenapine 2.5 and $5 \mathrm{mg}$ b.i.d. than for placebo, both asenapine groups failed to separate from placebo on the Hochberg-corrected primary analysis of change in PANSS total score from baseline to day 56. The study was designed to have power to detect an 8 point difference, or an effect size of 0.5 , in PANSS total score between asenapine and placebo at day 56; however, the anticipated treatment response and effect size may have been overestimated for this largely outpatient population of adolescents, because the actual treatment response was -4.8 for asenapine $2.5 \mathrm{mg}$ b.i.d. and -5.6 for asenapine $5 \mathrm{mg}$ b.i.d., and effect sizes were lower than expected ( 0.30 for asenapine $2.5 \mathrm{mg}$ b.i.d. and 0.35 for asenapine $5 \mathrm{mg}$ b.i.d.). A change of -0.5 SD is considered to be a clinically significant change in PANSS total score in adults, or typically 8 points on this scale, and the SD in the present study was as anticipated. The assumption of an 8 point difference was derived from the adult asenapine schizophrenia program and publications for other antipsychotic compounds (aripiprazole and quetiapine) that were registered for adolescents (1217 years of age when randomly assigned to treatment) with schizophrenia (Findling et al. 2008, 2012). In statistical sensitivity analyses (data not shown), differences between asenapine and placebo on the PANSS total score were consistently in the range of -5 points for asenapine $2.5 \mathrm{mg}$ bid and -6 points for asenapine $5 \mathrm{mg}$ b.i.d. Differences in clinical practice between the United States and non-United States sites that recruited adolescents with schizophrenia for this study did not appear to influence the results, as the treatment-by-region interaction was not significant in the MMRM analysis. Likewise, the placebo response on the PANSS total score $(-17.1$ points) was in the range observed with other agents in both positive and failed studies of schizophrenia in adolescents (Findling et al. 2008, 2012, 2013).

The numerical improvements attained in PANSS total score during the acute phase were maintained or increased over the course of the 26 week flexible-dose OLE, in which the mean 
average daily dose indicated that most subjects received asenapine $5 \mathrm{mg}$ b.i.d. In addition, the subjects who transitioned to asenapine in the OLE after receiving placebo during the acute phase essentially achieved the same level of response as the continuous asenapine group by the end of the 26 week extension study. The $5 \mathrm{mg}$ b.i.d. dose is the lowest approved dose for adults with schizophrenia (SAPHRIS PI 2014), whereas the $2.5 \mathrm{mg}$ b.i.d. asenapine dose was selected for the present trial based on a pharmacokinetic and tolerability study (Dogterom et al. 2012) with the aim of evaluating whether this lower dose might demonstrate efficacy in this potentially more vulnerable adolescent population. Although the primary end-point was not met for either dose, asenapine $5 \mathrm{mg}$ b.i.d. was associated with improvements in several exploratory secondary efficacy end-points. Statistically significant differences between asenapine $5 \mathrm{mg}$ b.i.d. and placebo at day 56 were observed for the CGI-S score, PANSS positive subscale score, and PANSS $30 \%$ responder rate; these findings suggest that subjects receiving the $5 \mathrm{mg}$ b.i.d. dose may have experienced some benefit from asenapine treatment during the acute phase.

With no clear superiority or differential symptom reduction among atypical and typical antipsychotic agents, differential adverse event profiles may be a primary consideration when selecting treatment for an adolescent with EOS (Sikich et al. 2008; Findling et al. 2010; Kumar et al. 2013). The sublingual formulation of asenapine was generally acceptable, because there were no significant differences in the hypoesthesia oral/dysgeusia combined end-point, and only a small increase in this event for the placebotreated subjects who switched to asenapine in the OLE. As expected, the somnolence/sedation/hypersomnia composite end-point was observed more frequently in the asenapine groups than in the placebo group; however, these events were not a common cause of treatment discontinuation (one subject in the OLE) and were generally considered mild to moderate in severity and transient in nature. Likewise for akathisia, which showed a signal for doseresponse in the acute phase, the incidence of this TEAE was lower in the OLE than in the acute phase, and no subjects discontinued because of this event. The numerically greater incidence of EPS in the asenapine $5 \mathrm{mg}$ group, combined with greater use of concomitant medications to treat EPS symptoms, suggests a dose-related signal. Overall, the AE profile in the placebo/asenapine group during the OLE was as expected based on the asenapine AE rates during the acute phase, and the lower rates in the continuous asenapine group during the OLE suggest that the $5 \mathrm{mg}$ b.i.d. dose was well tolerated.

Weight gain occurs in some adults treated with asenapine and has been reported with other atypical antipsychotic medications in adolescents (De Hert et al. 2011). In the present study, weight and BMI were monitored to determine potential clinically significant weight gain and weight gain in excess of normal growth. Because schizophrenia is a chronic illness that may require lifelong treatment, it is important to understand the potential metabolic effects of treatmentrelated weight gain, particularly because weight gain in adolescents taking atypical antipsychotics might be greater than what is observed in adults. Asenapine treatment was associated with weight gain, increases in fasting insulin, and other metabolic abnormalities in some patients. Overall, the data suggest that asenapine-treated adolescents may experience an initial increase in weight, followed by stabilization and minimal change during up to 26 weeks of additional treatment. Also consistent with the known safety profile of atypical antipsychotic medications with dopamine-antagonistic activity (Peuskens et al. 2014), asenapine treatment was associated with an increase in prolactin concentrations compared with placebo. In the present study, few subjects in the OLE had prolactin-associated AEs, and no dose-response was noted in the acute trial.

Low rates of remission, low effect size of medications, and the potential for adverse events, particularly metabolic abnormalities with long-term treatment, underscore the need for further study of antipsychotic medications in the adolescent population (Masi and Liboni 2011). Although statistically significant efficacy of asenapine in adolescents was not demonstrated in the present study, safety data through 34 weeks of treatment suggest that asenapine was generally well tolerated; and the safety profile in adolescents was consistent with that in adults with schizophrenia. Use of an asenapine dose lower ( $2.5 \mathrm{mg}$ b.i.d.) than that approved for adults, combined with careful titration to the $5 \mathrm{mg}$ b.i.d. dose, which is the recommended dose in adults, appeared to be successful in potentially mitigating unexpected adverse reactions in this adolescent population.

\section{Conclusions}

Although improvements in PANSS total score during the 8 week acute phase were numerically greater for both asenapine 2.5 and $5 \mathrm{mg}$ b.i.d. than for placebo, the differences did not achieve statistical significance. The two asenapine doses had safety and tolerability profiles that, overall, were similar during the acute phase, except for an apparent dose-response for clinically significant weight gain, EPS, and fasting glucose elevation. The numerical improvements attained in PANSS total score and CGI-S score during the acute phase were maintained or increased over the course of the 26 week flexible-dose OLE. No new or unexpected safety concerns were detected during up to 34 weeks of asenapine treatment in this adolescent population with schizophrenia.

\section{Clinical Significance}

We report results from the first acute, double-blind, randomized, placebo-controlled trial of asenapine $2.5 \mathrm{mg}$ and $5 \mathrm{mg}$ b.i.d. in adolescents with schizophrenia. These doses were selected based on the results of a previously conducted tolerability and pharmacokinetic study. Although the efficacy of asenapine $5 \mathrm{mg}$ b.i.d. and $10 \mathrm{mg}$ b.i.d. in adult inpatients with schizophrenia has been established, in the present adolescent study the PANSS total scores in the asenapine groups did not separate from placebo after 8 weeks of therapy. Lack of statistical significance may, in part, have resulted from overestimating the expected treatment effect in this predominately outpatient adolescent population. Differences between subjects recruited in the United States versus those recruited in other geographic regions did not appear to influence the results. Exploratory secondary efficacy parameters suggest a potential signal for treatment benefit with $5 \mathrm{mg}$ b.i.d. dose. Asenapine was generally well tolerated in adolescents for up to 34 weeks of treatment, with a safety profile consistent with that in adults with schizophrenia.

\section{Acknowledgments}

The authors thank all subjects and investigators who participated in these studies. Medical writing services were provided by Cathryn M. Carter of Arbor Communications, Inc; these services were funded by Forest Research Institute, Inc, an affiliate of Actavis Inc.

\section{Disclosures}

Dr. Findling receives or has received research support from, or acted as a consultant and/or served on a speaker's bureau for 
Alcobra, Alexza Pharmaceuticals, American Academy of Child \& Adolescent Psychiatry, American Physician Institute, American Psychiatric Press, AstraZeneca, Bracket, Bristol-Myers Squibb, Clinsys, CogCubed, Cognition Group, Coronado Biosciences, Dana Foundation, Forest, GlaxoSmithKline, Guilford Press, Johns Hopkins University Press, Johnson \& Johnson, KemPharm, Lilly, Lundbeck, Merck, NIH, Novartis, Noven, Otsuka, Oxford University Press, Pfizer, Physicians Postgraduate Press, Purdue, Rhodes Pharmaceuticals, Roche, Sage, Seaside Pharmaceuticals, Shire, Stanley Medical Research Institute, Sunovion, Supernus Pharmaceuticals, Transcept Pharmaceuticals, Validus, and WebMD. Drs. Landbloom and Mackle are employees of and own stock in Merck. Dr. Braat was a Merck employee at the time the study was conducted; has no financial disclosures. Dr. Pallozzi was a Merck employee at the time the study was conducted, and owns stock in Merck. Drs. Hundt and Mathews are employees of and own stock in Actavis. Dr. Wamboldt receives research funding from Forest, Pfizer, and Sunovion, as well as royalties from APA Press and Singer.

\section{References}

American Psychiatric Association: Diagnostic and Statistical Manual of Mental Disorders, 4th ed., Text Revision. Washington, DC: American Psychiatric Association; 2000.

American Psychiatric Association: Practice Guideline for the Treatment of Patients with Schizophrenia, 2nd ed. Arlington, VA: American Psychiatric Association, 2004.

Beratis S, Gabriel J, Hoidas S: Age at onset in subtypes of schizophrenic disorders. Schizophr Bull 20:287-296, 1994.

Centers for Disease Control and Prevention: A SAS Program for the 2000 CDC Growth Charts (ages 0 to $<20$ y), 2014. Available at http://www.cdc.gov/nccdphp/dnpao/growthcharts/resources/sas.htm. Accessed October 7, 2014.

De Hert M, Dobbelaere M, Sheridan EM, Cohen D, Correll CU: Metabolic and endocrine adverse effects of second-generation antipsychotics in children and adolescents: A systematic review of randomized, placebo controlled trials and guidelines for clinical practice. Eur Psychiatry 26:144-158, 2011.

Dogterom P, Robert Riesenberg R, Lesem M, de Greef R, Miltenburg A, Landbloom R, Troyer MD: Asenapine pharmacokinetics and tolerability in a pediatric population with a psychotic disorder: influence of dosing regimen. Poster presented at the 59th Annual Meeting of the American Academy of Child and Adolescent Psychiatry, October 23-28, 2012, San Francisco, CA.

Findling RL, Cavuş I, Pappadopulos E, Vanderburg DG, Schwartz JH, Gundapaneni BK, DelBello MP: Ziprasidone in adolescents with schizophrenia: results from a placebo-controlled efficacy and longterm open-extension study. J Child Adolesc Psychopharmacol 23:531-544, 2013.

Findling RL, Johnson JL, McClellan J, Frazier JA, Vitiello B, Hamer RM, Lieberman JA, Ritz L, McNamara NK, Lingler J, Hlastala S, Pierson L, Puglia M, Maloney AE, Kaufman EM, Noyes N, Sikich L: Double-blind maintenance safety and effectiveness findings from the Treatment of Early-Onset Schizophrenia Spectrum (TEOSS) study. J Am Acad Child Adolesc Psychiatry 49:583-594; quiz 632, 2010.

Findling RL, McKenna K, Earley WR, Stankowski J, Pathak S: Efficacy and safety of quetiapine in adolescents with schizophrenia investigated in a 6-week, double-blind, placebo-controlled trial. J Child Adolesc Psychopharmacol. 22:327-342, 2012.

Findling RL, Robb A, Nyilas M, Forbes RA, Jin N, Ivanova S, Marcus $\mathrm{R}$, McQuade RD, Iwamoto T, Carson WH: A multiple-center, randomized, double-blind, placebo-controlled study of oral ar- ipiprazole for treatment of adolescents with schizophrenia. Am J Psychiatry 2008 165:1432-1441, 2008.

Frazier JA, Giuliano AJ, Johnson JL, Yakutis L, Youngstrom EA, Breiger D, Sikich L, Findling RL, McClellan J, Hamer RM, Vitiello B, Lieberman JA, Hooper SR: Neurocognitive outcomes in the Treatment of Early-Onset Schizophrenia Spectrum Disorders study. J Am Acad Child Adolesc Psychiatry 51:496-505, 2012.

Frazier JA, McClellan J, Findling RL, Vitiello B, Anderson R, Zablotsky B, Williams E, McNamara NK, Jackson JA, Ritz L, Hlastala SA, Pierson L, Varley JA, Puglia M, Maloney AE, Ambler D, Hunt-Harrison T, Hamer RM, Noyes N, Lieberman JA, Sikich L: Treatment of early-onset schizophrenia spectrum disorders (TEOSS): Demographic and clinical characteristics. J Am Acad Child Adolesc Psychiatry 46:979-988, 2007.

Guy W: The Clinical Global Impressions Scale. In: ECDEU Assessment Manual for Psychopharmacology Rev. Ed. Rockville, MD: National Institute of Mental Health; 1976; pp 157-169.

Haas M, Unis AS, Armenteros J, Copenhaver MD, Quiroz JA, Kushner SF: A 6-week, randomized, double-blind, placebo-controlled study of the efficacy and safety of risperidone in adolescents with schizophrenia. J Child Adolesc Psychopharmacol 19:611-621, 2009a.

Haas M, Eerdekens M, Kushner S, Singer J, Augustyns I, Quiroz J, Pandina G, Kusumakar V: Efficacy, safety and tolerability of two dosing regimens in adolescent schizophrenia: double-blind study. Br J Psychiatry 194:158-164, 2009b.

Hafner H, Maurer K, Loffler W, Riecher-Rossler A: The influence of age and sex on the onset and early course of schizophrenia. Br J Psychiatry 162:80-86, 1993.

International Diabetes Federation: Criteria of metabolic syndrome in children and adolescents, 2014. Available at http://www.idf.org/ metabolic-syndrome/children/criteria?language $=\mathrm{fr}$. Accessed October 8, 2014.

Introductory Guide for Standardized MedDRA Queries (SMQs) Version 15.1. MSSO-DI-6226-15.1.0, September 2012. Available at http://www.meddra.org/sites/default/files/guidance/file/SMQ_ intguide_15_1_English_0.pdf Accessed October 23, 2014.

Introductory Guide for Standardized MedDRA Queries (SMQs) Version 16.0. MSSO-DI-6226-16.0, March 2013. Available at http:// www.meddra.org/sites/default/files/guidance/file/smq_intguide_16_0 _english.pdf Accessed October 23, 2014.

Kane JM, Cohen M, Zhao J, Alphs L, Panagides J: Efficacy and safety of asenapine in a placebo- and haloperidol-controlled trial in patients with acute exacerbation of schizophrenia. J Clin Psychopharmacol 30:106-115, 2010.

Kane JM, Mackle M, Snow-Adami L, Zhao J, Szegedi A, Panagides $\mathrm{J}$ : A randomized placebo-controlled trial of asenapine for the prevention of relapse of schizophrenia after long-term treatment. J Clin Psychiatry 72:349-355, 2011.

Kay SR, Fiszbein A, Opler LA: The positive and negative syndrome scale (PANSS) for schizophrenia. Schizophr Bull 13:261-276, 1987.

Kryzhanovskaya L, Schulz SC, McDougle C, Frazier J, Dittmann R, Robertson-Plouch C, Bauer T, Xu W, Wang W, Carlson J, Tohen M: Olanzapine versus placebo in adolescents with schizophrenia: A 6-week, randomized, double-blind, placebo-controlled trial. J Am Acad Child Adolesc Psychiatry 48:60-70, 2009.

Kumar A, Datta SS, Wright SD, Furtado VA, Russell PS: Atypical antipsychotics for psychosis in adolescents. Cochrane Database Syst Rev 10:CD009582, 2013.

Masi G, Liboni F: Management of schizophrenia in children and adolescents: Focus on pharmacotherapy. Drugs 71:179-208, 2011.

McClellan J, Stock S, American Academy of Child and Adolescent Psychiatry (AACAP) Committee on Quality Issues (CQI): Practice 
parameter for the assessment and treatment of children and adolescents with schizophrenia. J Am Acad Child Adolesc Psychiatry 52:976-990, 2013.

McIntyre RS, Wong R: Asenapine: A synthesis of efficacy data in bipolar mania and schizophrenia. Clin Schizophr Relat Psychoses. 5:217-220, 2012.

Miettinen O, Nurminen M: Comparative analysis of two rates. Stat Med 4:213-226, 1985.

Peuskens J, Pani L, Detraux J, De Hert M: The effects of novel and newly approved antipsychotics on serum prolactin levels: a comprehensive review. CNS Drugs 28:421-453, 2014.

Potkin SG, Cohen M, Panagides J: Efficacy and tolerability of asenapine in acute schizophrenia: a placebo- and risperidone-controlled trial. J Clin Psychiatry 68:1492-1500, 2007.

SAPHRIS $^{\mathrm{TM}}$ (asenapine) US prescribing information. Forest Pharmaceuticals, Inc, Saint Louis MO. Merck Sharp \& Dohme BV (used by Forest Pharmaceuticals, Inc. under license), 2014.

Sikich L, Frazier JA, McClellan J, Findling RL, Vitiello B, Ritz L, Ambler D, Puglia M, Maloney AE, Michael E, De Jong S, Slifka K,
Noyes N, Hlastala S, Pierson L, McNamara NK, Delporto-Bedoya D, Anderson R, Hamer RM, Lieberman JA: Double-blind comparison of first- and second-generation antipsychotics in early-onset schizophrenia and schizo-affective disorder: Findings from the treatment of early-onset schizophrenia spectrum disorders (TEOSS) study. Am J Psychiatry 165:1420-1431, 2008.

Singh J, Robb A, Vijapurkar U, Nuamah I, Hough D: A randomized, double-blind study of paliperidone extended-release in treatment of acute schizophrenia in adolescents. Biol Psychiatry 70:1179-1187, 2011.

Address correspondence to:

Robert L Findling, $M D, M B A$

Department of Child \& Adolescent Psychiatry Johns Hopkins Children's Center 1800 Orleans $\mathrm{St}$ Baltimore, MD 21287

E-mail: RFindli1@jhmi.edu 